\title{
Editorial
}

\section{Impulse-Based Manufacturing Technologies}

\author{
Verena Psyk (1)
}

Citation: Psyk, V. Impulse-Based Manufacturing Technologies. J.

Manuf. Mater. Process. 2021, 5, 133. https: / / doi.org/10.3390/ jmmp5040133

Received: 4 December 2021 Accepted: 7 December 2021 Published: 9 December 2021

Publisher's Note: MDPI stays neutral with regard to jurisdictional claims in published maps and institutional affiliations.

Copyright: (C) 2021 by the author. Licensee MDPI, Basel, Switzerland. This article is an open access article distributed under the terms and conditions of the Creative Commons Attribution (CC BY) license (https:// creativecommons.org/licenses/by/ $4.0 /)$.
Fraunhofer Institute for Machine Tools and Forming Technology IWU, 09126 Chemnitz, Germany; verena.psyk@iwu.fraunhofer.de

Modern manufacturing faces extensive technological and economic challenges to remain competitive under the current political and social conditions. Complex component geometries must be formed with high precision from materials that often provide limited formability. Joining technology must enable connections between different material combinations so that the resulting joints meet high requirements in terms of, e.g., mechanical strength, electrical conductivity, or tightness. Cutting operations must ensure a high-quality cut surface for materials of different strengths. In all areas, cost effectiveness, resource efficiency, and flexibility must be considered, and the manufacturing industry must be able to react quickly to changing boundary conditions and adapt their production in the sense of a resilient system. The clever use of velocity effects can help to meet these demands. This especially concerns impulse-based manufacturing technologies, in which the required energy acts within a very short period of time and suddenly accelerates workpiece areas to very high velocities. The correspondingly high strain rates, together with inertia and adiabatic effects, affect the behavior of many materials, resulting in technological benefits such as improved formability, reduced localizing, springback, extended possibilities regarding the production of high-quality multi material joints, and burr-free cutting. Furthermore, it is often possible to apply smaller and simpler presses.

This Special Issue of JMMP presents the current research findings, which focus on exploiting the full potential of impulse-based processes by providing a deep understanding of the technology and material behavior and detailed knowledge of sophisticated process and equipment design. The range of considered processes covers electromagnetic forming and joining by magnetic pulse welding, electrohydraulic forming, the use of vaporizing foil actuators, and adiabatic cutting with hydraulically driven presses. The presented work spans from basic investigations via application-oriented research to the development of industrial series processes.

In recent years, magnetic pulse welding - an application of electromagnetic forming that allows for the impact welding of various material combinations, including ones that are not compatible in conventional fusion-welding processes-has been a topic of interest in research and among industrial users. Corresponding with this trend, several papers in this Special Issue are dedicated to this technology: Faes et al. investigate the magnetic pulse welding of copper and steel tubes with and without an internal support. They use a coupled numerical simulation to quantify the collision parameters (impact angle and velocity) and predict the resulting shape of the joint. This shape is verified experimentally and fundamental correlations between influencing process parameters, collision properties and joint characteristics are identified [1]. Complementarily to this, Zhang and Kinsey study the tube-to-rod welding of aluminum to titanium and copper. They analyze the weld morphology via microstructural analysis and multiscale simulation. The research shows that yield strength and the density of the joining partners influence the wave formation and shear stresses are decisive, while shear velocity and contact pressure seem to have a minor influence [2]. Drehmann et al. focus on sheet metal magnetic pulse welding of aluminum to press-hardening steel and prove, via lap shear tests, that high quality is achievable. Similar to [1], they determine the collision parameters via coupled numerical simulation and deduce a quantitative collision-parameter-based process window 
for the material combination. They also perform an in-depth microstructural analysis and correlate the results with the mechanical quality of the welds [3]. Khalil et al. consider a special variant of magnetic pulse welding, which is suitable for the spot welding of metal sheets. They focus on tool design and assess different geometries and materials with regard to their efficiency and lifetime performance. In this context, again, the impact velocity is calculated, and the resulting aluminum steel joints are evaluated in quasistatic shear tests and fatigue tests [4]. These contributions reflect the significance of the collision properties in magnetic pulse welding. However, the technology does not allow for the direct adjustment of these important parameters, and even their measurement is hardly possible. To overcome these restrictions, Groche and Niessen present a model experiment that allows for the direct setting of the collision velocity and angle, independently of each other. They quantify a process window for aluminum/copper welds and compare this to the corresponding process windows identified for aluminum/aluminum and copper/copper welds. Microstructural investigations help to evaluate the weld quality and identify bonding mechanisms [5]. Similarly, Prasad et al. present a model setup that allows for an investigation of high-speed collision processes. They use a vaporizing foil actuator to accelerate a projectile to velocities in the range of $300-400 \mathrm{~m} / \mathrm{s}$. The setup serves for impulse-based manufacturing, such as collision welding or powder compaction, as well as for characterizing, e.g., the spall strength of materials in shock physics [6].

In addition to magnetic pulse welding, shaping by electromagnetic forming is considered in some contributions to this Special Issue. While earlier work dedicated to this technology focused on modelling and understanding the general deformation course, the work presented here focusses on equipment design and the development of complex industrial parts. Goyal et al. present fundamental results regarding the mechanical loads acting on the coil. They consider skin and proximity effects to numerically calculate the current density distribution and the resulting deformation of the coil winding as a function of the arrangement of the individual winding turns relative to each other and the workpiece [7]. As a supplement, Beckschwarte et al. examined the molding tools. They point out that, when forming thin foils, both the mechanical and electrical properties of the dies must be considered because, for this type of workpiece, the shielding of the magnetic field is not very effective. To avoid significant reductions in the process efficiency, the die materials should feature low electrical conductivity and high permeability [8]. Avrillaud et al. comprehensively reviewed how high strain rates can improve the formability of materials and applied this knowledge to industrial applications from the automotive sector, luxury products, or hadron collider components. The application examples consider the formation of deep or complex geometries, embossing, and post-forming to shape sharp edges. They show that, depending on the manufacturing task, electromagnetic or electrohydraulic forming could be suitable [9]. The contribution of Mamutov et al. also deals with the implementation of electrohydraulic forming in industrial manufacturing. They present a simple stepwise process design method: first, critical areas requiring a high forming pressure are identified; then, a hydrodynamic simulation serves to optimize the pressure chamber and, finally, a simple preform design method allows for the strains to be redistributed in the workpiece [10].

Compared to the technologies considered so far, high-speed impact cutting with hydraulically driven presses is a relatively slow process. However, the punch speed can still reach up to $10 \mathrm{~m} / \mathrm{s}$, and corresponding strain rates are in the range of $10^{3} / \mathrm{s}$, so the technology can still benefit from strain rate, inertia, and adiabatic heating. Winter et al. investigate the formation of adiabatic shear bands and the corresponding geometric accuracy of the cut surface under different process parameters. Specifically, they consider the influences of the relative clearance and the corresponding stress state, impact velocity, and impact energy [11].

All contributions to this Special Issue use numerical simulation to visualize and quantify process parameters, which can hardly be measured. Obviously, the quality of such simulations significantly depends on the implemented material model and the accuracy of 
the material parameters under the specific technological circumstances, such as strain rate and triaxiality. Therefore, technology-adapted material characterization and modelling is highly relevant in impulse-based manufacturing. Silva et al. suggest a me-thodology for the mechanical characterization and modelling of materials under extreme load conditions considering strain, strain rate, temperature, and state of stress [12]. Al-though the validation in this paper is based on metal cutting, these load conditions show comprehensive similarities with the situation in impulse-based manufacturing, so the approach is relevant and could benefit these technologies, too. The consequent improvement in the simulation via establishing efficient coupled and multiscale tools, as well as well-adapted material models, provides a prerequisite for the future implementation of digitalization and artificial intelligence, and thus contributes to the development of smart, impulse-based manufacturing processes.

Funding: This research received no external funding.

Conflicts of Interest: The author declares no conflict of interest.

\section{References}

1. Faes, K.; Shotri, R.; De, A. Probing Magnetic Pulse Welding of Thin-Walled Tubes. J. Manuf. Mater. Process. 2020, 4, 118. [CrossRef]

2. Zhang, S.; Kinsey, B.L. Influence of Material Properties on Interfacial Morphology during Magnetic Pulse Welding of Al1100 to Copper Alloys and Commercially Pure Titanium. J. Manuf. Mater. Process. 2021, 5, 64. [CrossRef]

3. Drehmann, R.; Scheffler, C.; Winter, S.; Psyk, V.; Kräusel, V.; Lampke, T. Experimental and Numerical Investigations into Magnetic Pulse Welding of Aluminum Alloy 6016 to Hardened Steel 22MnB5. J. Manuf. Mater. Process. 2021, 5, 66. [CrossRef]

4. Khalil, C.; Marya, S.; Racineux, G. Magnetic Pulse Welding and Spot Welding with Improved Coil Efficiency-Application for Dissimilar Welding of Automotive Metal Alloys. J. Manuf. Mater. Process. 2020, 4, 69. [CrossRef]

5. Groche, P.; Niessen, B. The Energy Balance in Aluminum-Copper High-Speed Collision Welding. J. Manuf. Mater. Process. 2021, 5, 62. [CrossRef]

6. Prasad, K.S.; Mao, Y.; Vivek, A.; Niezgoda, S.R.; Daehn, G.S. A Rapid Throughput System for Shock and Impact Characterization: Design and Examples in Compaction, Spallation, and Impact Welding. J. Manuf. Mater. Process. 2020, 4, 116. [CrossRef]

7. Goyal, S.P.; Lashkari, M.; Elsayed, A.; Hahn, M.; Tekkaya, A.E. Analysis of Proximity Consequences of Coil Windings in Electromagnetic Forming. J. Manuf. Mater. Process. 2021, 5, 45. [CrossRef]

8. Beckschwarte, B.; Langstädtler, L.; Schenck, C.; Herrmann, M.; Kuhfuss, B. Numerical and Experimental Investigation of the Impact of the Electromagnetic Properties of the Die Materials in Electromagnetic Forming of Thin Sheet Metal. J. Manuf. Mater. Process. 2021, 5, 18. [CrossRef]

9. Avrillaud, G.; Mazars, G.; Cantergiani, E.; Beguet, F.; Cuq-Lelandais, J.-P.; Deroy, J. Examples of How Increased Formability through High Strain Rates Can Be Used in Electro-Hydraulic Forming and Electromagnetic Forming Industrial Applications. J. Manuf. Mater. Process. 2021, 5, 96. [CrossRef]

10. Mamutov, A.V.; Golovashchenko, S.F.; Bessonov, N.M.; Mamutov, V.S. Electrohydraulic Forming of Low Volume and Prototype Parts: Process Design and Practical Examples. J. Manuf. Mater. Process. 2021, 5, 47. [CrossRef]

11. Winter, S.; Nestler, M.; Galiev, E.; Hartmann, F.; Psyk, V.; Kräusel, V.; Dix, M. Adiabatic Blanking: Influence of Clearance, Impact Energy, and Velocity on the Blanked Surface. J. Manuf. Mater. Process. 2021, 5, 35. [CrossRef]

12. Silva, T.E.F.; Gregório, A.V.L.; de Jesus, A.M.P.; Rosa, P.A.R. An Efficient Methodology towards Mechanical Characterization and Modelling of 18Ni300 AMed Steel in Extreme Loading and Temperature Conditions for Metal Cutting Applications. J. Manuf. Mater. Process. 2021, 5, 83. [CrossRef] 